Revista Destaques Acadêmicos, Lajeado, v. 11, n. 4, 2019. ISSN 2176-3070

DOI: http://dx.doi.org/10.22410/issn.2176-3070.v11i4a2019.2398

http://www.univates.br/revistas

\title{
APRENDIZAGEM BASEADA EM PROBLEMAS COMO METODOLOGIA ATIVA NA EDUCAÇÃO PROFISSIONAL
}

\author{
Niumar André Klein ${ }^{1}$, Edson Moacir Ahlert ${ }^{2}$
}

Resumo: A demanda cada vez maior do mundo do trabalho por profissionais com características voltadas à capacidade de iniciativa, flexibilidade, autonomia e trabalho em equipe, levou as instituições de ensino profissionalizante à necessidade de se adaptarem a essa nova realidade social. Para formar esse novo perfil de estudante a Educação Profissional deve deixar de lado as metodologias tradicionais de ensino focadas na memorização e na transmissão do conteúdo e promover metodologias ativas cuja aprendizagem se dá por meio da reflexão e problematização de experiências reais. Portanto, com este artigo, objetiva-se apresentar a experiência de aula na promoção da utilização da metodologia ativa de Aprendizagem Baseada em Problemas (PBL) para o desenvolvimento de uma atividade dita situação-problema alinhada ao contexto de formação profissional técnica dos alunos. Após a contextualização teórica das metodologias ativas, da PBL e de sua relação com a Educação Profissional, apresentase o planejamento, a atividade e o processo pelo qual conduziu-se este estudo. Como avaliação da atividade propôs-se um questionário cujos dados levaram a uma análise quali-quantitativa da percepção do discente no seu processo de aprendizado. Os resultados da análise levaram à conclusão de que o método PBL contribuiu de modo relevante para o processo de aprendizagem dos alunos, logo, contribuindo para a formação do perfil profissional desejado.

Palavras-chave: Metodologias ativas. Aprendizagem baseada em problemas. Educação profissional.

\section{INTRODUÇÃO}

O surgimento e o desenvolvimento acelerado das Tecnologias da Informação e Comunicação (TICs) trouxeram novos desafios aos processos produtivos instaurados até então, bem como aos seculares métodos de ensino e aprendizagem. $\mathrm{O}$ aluno de antes, formado e preparado para exercer tarefas

1 Bacharel em Engenharia de Controle e Automação, Professor do Centro de Educação Profissional - CEP - Univates.

2 Professor da Univates. Mestre em Ambiente e Desenvolvimento. 
repetitivas, pouco criativas e sem necessidade de pensamento crítico, precisa evoluir para preencher espaços cada vez mais tecnológicos e dinâmicos. $\mathrm{O}$ mercado de trabalho demanda por tais profissionais, o que por fim, acaba refletindo sobre as instituições de ensino e suas metodologias (BERBEL, 2011; BARBOSA; MOURA, 2013).

Este cenário é ainda mais contundente no âmbito da Educação Profissional, já que esta é responsável por formar especificamente os profissionais voltados às dimensões do trabalho (BRASIL, 1996). Sabe-se que esta força de trabalho, egressa do tradicional ensino profissionalizante, é preparada para o exercício de atividades que tangenciam a execução, a prática e da qual pouco se esperam atitudes voltadas para a autonomia, a análise crítica e a flexibilidade.

Decorrente das atuais movimentações tecnológicas e do desenvolvimento contínuo e dinâmico do conhecimento, os futuros profissionais precisam ser preparados para terem as condições necessárias de adaptação, inserção, manutenção e de continuidade nas posições de trabalho que ocuparão, cada qual com seus desafios e dificuldades associados aos eixos tecnológicos específicos de cada área do conhecimento. Seguindo pelo proposto por Barbosa e Moura (2013, p. 50): “Espera-se que os egressos da Educação Profissional e Tecnológica (EPT) sejam capazes de transitar com desenvoltura e segurança em um mundo cada vez mais complexo e repleto de tecnologias inovadoras".

Sendo assim, para Barbosa e Moura (2013), o plano de ensino das instituições educacionais deve afastar-se de métodos tradicionais, muito voltados à verbalização, à teorização e à utilização da memória e, investir, portanto, na aprendizagem significativa, contextualizada, orientada ao uso das TICs, priorizando os recursos da inteligência, a promoção de habilidades para solução de problemas e condução de projetos, para assim formar profissionais de conduta ética, com capacidade de iniciativa, criatividade, flexibilidade, autocontrole, comunicação, etc.

A necessidade de profissionais com as qualificações citadas justifica a inclusão de metodologias complementares à já habitual expositiva e dialogada nos planos de ensino dos cursos profissionalizantes. Como dito por Berbel (2011), as metodologias ativas têm condições de proporcionar a aprendizagem desejada, utilizando meios diversificados, a exemplo das TICs.

Portanto, com o intuito de potencializar a capacidade do aluno na solução individual e/ou coletiva de problemas decorrentes dos desafios de sua área de atuação e, ademais, contribuir para a formação e desenvolvimento do seu pensamento crítico, criatividade, iniciativa e autonomia, objetiva-se, com este trabalho, apresentar a experiência do professor autor na inserção de metodologias ativas de aprendizagem na disciplina de Eletrônica Digital dos cursos de uma instituição de ensino profissionalizante. Como forma de delimitar o contexto da aplicação das metodologias ativas, focou-se este estudo 
especificamente na modalidade de Aprendizagem Baseada em Problemas, do inglês, Problem-Based Learning (PBL).

A utilização do método PBL se justifica na afirmação de Berbel (2011, p. 32) quando diz que este "se diferencia dos demais, por constituir-se como o eixo principal do aprendizado técnico-científico numa proposta curricular". A disciplina trabalhada neste estudo faz parte do currículo de cursos técnicos vinculados ao eixo tecnológico Controle e Processos Industriais (BRASIL, 2008). Sendo assim, seus planos de ensino contemplam conteúdos associados à área das ciências exatas, portanto de cunho técnico-científico. Diante disso, tais disciplinas são aptas para a utilização da metodologia ativa de aprendizagem baseada em problemas.

O procedimento metodológico utilizado para o desenvolvimento do presente trabalho envolveu, inicialmente, o estudo prévio dos conteúdos requeridos pela ementa da disciplina, estes conduzidos via metodologias tradicionais, tais como aulas expositivas e dialogadas, aplicação de exercícios e trabalhos extraclasse. Cumprido o plano de aula tradicional, seguiu-se para a inserção da metodologia ativa PBL, propondo aos alunos uma atividade dita situação-problema, cujas características buscam atender ao objetivo traçado.

A tarefa foi planejada seguindo um processo estruturado em 5 fases para ser aplicado nas últimas 5 aulas da disciplina. A atividade encerra com a coleta da percepção pessoal dos alunos quanto à proposta de trabalho implementada mediante a aplicação de um questionário de cunho qualitativo. Os resultados obtidos a partir da análise da opinião dos estudantes conduzem para a argumentação da conclusão do estudo.

\section{METODOLOGIAS ATIVAS DE APRENDIZAGEM}

Diante do impasse pelo qual a educação formal vem passando em função das diversas mudanças na sociedade, necessitamos de alunos cada vez mais proativos, que se envolvam em atividades complexas que demandem atitude e poder de decisão, que sejam criativos e autônomos. Numa relação direta, precisamos igualmente de métodos adequados que desenvolvam tais competências (MORÁN, 2015).

Os "métodos adequados" aos quais Morán (2015) se refere acima, são métodos que visam eliminar ou, ao menos, reduzir a frustração pela pouca participação, desinteresse e desvalorização dos alunos quanto às estratégias de ensino, bem como a aulas rotineiras, enfadonhas e pouco dinâmicas às quais Diesel, Baldez e Martins (2017) fazem referência.

Seguindo nessa ideia, Morán (2015) sustenta que é por meio da promoção de desafios e atividades dosadas, planejadas, acompanhadas e avaliadas com o suporte das TICs que estaremos contribuindo para mobilizar as características desejadas, intelectuais, emocionais, pessoais e comunicacionais. Portanto sugere que as metodologias ativas de aprendizagem sejam: "[..] pontos de partida para 
avançar para processos mais avançados de reflexão, de integração cognitiva, de generalização, de reelaboração de novas práticas" (MORÁN, 2015, p. 18).

Buscando um significado para as metodologias ativas, chegamos a uma definição dada por Berbel (2011, p. 29) quando diz que tais métodos:

[...] baseiam-se em formas de desenvolver o processo de aprender, utilizando experiências reais ou simuladas, visando às condições de solucionar, com sucesso, desafios advindos das atividades essenciais da prática social, em diferentes contextos.

De acordo com Berbel (2011), e corroborando o que Morán (2015) sustenta, a utilização das metodologias ativas favorecem a atitude autônoma do aluno no momento em que este é submetido a oportunidades de problematização de situações, com abertura para escolha de conteúdos e caminhos que o levem a soluções criativas para os problemas através da reflexão, do estudo e da pesquisa. De Morán (2015, p. 18) ainda podemos acrescentar que: "Quanto mais aprendemos próximos da vida, melhor".

Logo, "se a prática de ensino favorecer no aluno as atividades de ouvir, ver, perguntar, discutir, fazer e ensinar, estaremos no caminho da aprendizagem ativa" (BARBOSA; MOURA, 2013, p. 55). Além disso, se na sua prática de ensino o professor fomentar a reflexão sobre problematizações da vida real, promover a autonomia e o trabalho em equipe e, por fim, atuar como mediador, orientador e facilitador, colocando o aluno no centro do processo de aprendizagem, estará pondo em prática as principais características das metodologias ativas conforme Diesel, Marchesan e Martins (2016) sintetizam na Figura 1. 
Figura 1 - Características das metodologias ativas de ensino

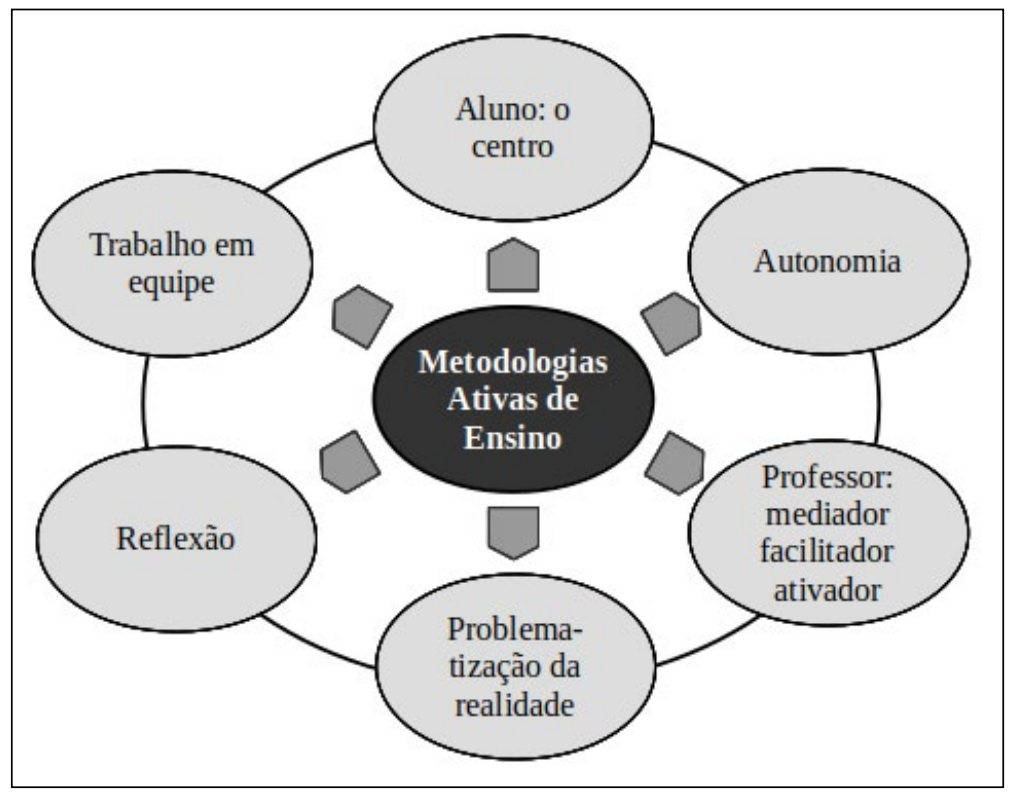

Fonte: Dos autores com base em Diesel, Marchesan e Martins (2016, p. 156).

Berbel (2011) ainda afirma que a curiosidade e, por consequência, o engajamento do aluno se dá à medida que este tem a liberdade de, durante a teorização do conteúdo, trazer elementos novos ainda não considerados pelo professor.

Cabe ressaltar ainda que as metodologias ativas representam um conjunto de métodos, cada qual com sua especificidade no processo da aprendizagem que, segundo Oliveira e Araújo (2015, p.1), compreendem a Instrução pelos Pares (Peer Instruction), a Aprendizagem Baseada em Problemas (Problem Based Learning), a Aprendizagem Baseada em Projeto (Project Based Learning), a Aprendizagem Baseada em Equipe (Team Based Learning) e o Estudo de Caso (Case of Study).

Por fim, o mundo do trabalho requer dos futuros profissionais um bom desempenho na solução de problemas e na interação social. Souza e Dourado (2015) afirmam que a PBL é a metodologia capaz de promover atividades com maior cooperação grupal e, com isso, desenvolver habilidades interpessoais e o espírito em equipe. Mostra-se, assim, mais um motivo para a escolha da PBL como metodologia de desenvolvimento deste estudo.

Sendo assim, a próxima seção abordará os principais pressupostos teóricos que envolvem a metodologia de Aprendizagem Baseada em Problemas. 


\section{APRENDIZAGEM BASEADA EM PROBLEMAS}

De acordo com Ribeiro (2010, p. 13) e Borochovicius e Tortella (2014, p. 268), a PBL é, em sua essência, caracterizada pelo uso de problemas da vida real no estímulo do pensamento crítico e das habilidades de solução e obtenção de conceitos fundamentais da área de estudo em questão.

Barbosa e Moura (2013, p. 58), de modo mais sucinto e direto, fundamentam a PBL como "o uso contextualizado de uma situação-problema para o aprendizado autodirigido". Logo, diferentemente dos métodos convencionais cujo objetivo é a transmissão do conhecimento centrado no professor, na PBL o aluno é o centro do processo, deixando de ser um receptor passivo da informação para ser um agente ativo do seu próprio aprendizado.

Já Berbel (2011, p. 34) sustenta que o aluno, diante de problemas e/ ou desafios, mobiliza o seu potencial intelectual enquanto estuda para compreendê-los e ou superá-los, produzindo, assim, informação em função do que precisa responder ou equacionar. No decorrer deste processo, é possível que o aluno, gradativamente, desenvolva o espírito científico, o pensamento crítico, o pensamento reflexivo, adquira valores éticos, tornando-se autônomo na formação do ser humano e do futuro profissional.

Diferentemente de outras metodologias que também fazem uso da problematização de situações para fixação de estudos teóricos, a PBL apresenta o problema desde o início do estudo, direcionando, motivando e focando a aprendizagem (RIBEIRO, 2010). Em decorrência disso, funções mais amplas e complexas são exigidas do docente. Este passa a ser responsável, também, por mediar discussões; atuar para manter grupos de alunos focados em um problema ou questão específica; motivar alunos a se envolverem com as tarefas requeridas no processo de busca de solução; estimular o uso da função de pensar, observar, raciocinar e entender (BARBOSA; MOURA, 2013, p. 60).

Por fim, para Barbosa e Moura (2013), a metodologia de Aprendizagem Baseada em Problemas procura transformar um problema em motivação para o aprendizado autodirigido, propiciando a construção do conhecimento em ambiente de colaboração mútua.

\section{PBL NA EDUCAÇÃO PROFISSIONAL}

Conforme Barbosa, Gontijo e Santos (2003), o setor produtivo, a partir de 1980, passou a demandar por profissionais de atitude mais flexível diante da chegada de novas tecnologias ao Brasil. Até então, as escolas técnicas formavam trabalhadores treinados e padronizados para uma atividade inerte. Em consequência disso, a Educação Profissional passou a necessitar de investimentos em inovação e diversificação de suas práticas de ensino.

Ao recorrermos à legislação brasileira, a Educação Profissional, segundo Brasil (2012), em seu Artigo 6 ${ }^{\circ}$, inciso VIII, tem suas estratégias educacionais 
norteadas pela contextualização, flexibilidade e interdisciplinaridade, favorecendo a compreensão de significados e a integração entre a teoria e a vivência da prática profissional. Sendo assim, a Educação Profissional, para alinhar-se às novas demandas sociais, deve apostar na "utilização de metodologias ativas para desenvolver no aluno a capacidade de aprender a aprender" (BARBOSA; GONTIJO; SANTOS, 2003, p. 1).

Nesse sentido, as características da metodologia PBL se enquadram muito bem, pois, a exemplo, estimulam a aprendizagem voltada a situações que o aluno deverá conhecer e dominar para o exercício de sua profissão (BERBEL, 2011, p. 32). Inclusive, Barbosa e Moura (2013) e Barbosa, Gontijo e Santos (2003) afirmam que as atuais movimentações sociais e tecnológicas favorecem a inclusão das TICs no processo de formação do profissional. Portanto torna-se evidente a importância de combinar a problematização de situações reais com o uso de tecnologias da informação para a potencialização de uma aprendizagem alinhada com as necessidades educacionais atuais.

As dadas situações problema, as quais o professor deve trabalhar de modo cooperativo com seus alunos e que são objeto de interesse deste estudo, são melhor descritas por Meirieu (1999, apud Borochovicius e Barboza Tortella, 2014, p. 274): "A situação-problema coloca o discente em ação de forma interativa com a realidade, que desestabiliza e reestabiliza em função das intervenções promovidas pelo docente e é nesta interação que se constrói, muitas vezes irracionalmente, a racionalidade".

Assim sendo, constata-se que a metodologia PBL possui uma relação estreita com a Educação Profissional por:

[...] ser a ponte que aproxima o ensino da prática empresarial, reduzindo assim o abismo entre a teoria e a prática na sala de aula, pois permite que o aluno, ao trabalhar cooperativamente em pequenos grupos, solucione com o auxílio de tecnologia e recursos de pesquisas problemas reais que emergem da sociedade (ENEMARK; KJAERSDAM apud MARTINS, 2013, p. 23).

\section{PROCEDIMENTOS METODOLÓGICOS}

Nesta seção é feito o relato de como foi desenvolvida a sequência metodológica no uso da aprendizagem baseada em problemas na disciplina de Eletrônica Digital dos Cursos Técnicos em Eletroeletrônica e Automação Industrial de uma instituição de ensino técnico do Vale do Taquari/RS. A disciplina foi ministrada durante o primeiro semestre de 2017, sendo a turma composta por 24 alunos, todos do sexo masculino e de formação média completa. A faixa etária destes era entre os 18 e 30 anos de idade.

As 13 primeiras aulas, de um total de 18, foram ministradas segundo o método tradicional, ou seja, de acordo com a metodologia expositiva e 
dialogada. A partir da $14^{\mathrm{a}}$ aula, tendo-se concluído o conteúdo obrigatório segundo a ementa da disciplina, utilizou-se o restante desta para desenvolver uma atividade seguindo a metodologia PBL.

Para desenvolver a metodologia PBL na disciplina de Eletrônica Digital, o professor e autor deste estudo, construiu uma situação-problema na qual buscou incorporar as seguintes características: 1 . Estar vinculada à ementa da disciplina; 2 . Promover o conhecimento prévio; 3 . Ser desafiadora e atrativa; 4. Potencializar o trabalho em equipe, o sentimento de responsabilidade e comprometimento; 5. Aproximar-se do contexto profissional.

Tal situação-problema, uma vez concebida, foi nomeada de "Controle Digital por Lógica Combinacional dos Estágios de Operação de um Secador de Grãos". A partir do próprio título, evidenciou-se a presença das matérias a serem trabalhadas e a relação com situações de cunho prático e profissional vinculadas às áreas da Eletrônica e Automação.

Para promover o trabalho em equipe subdividiu-se o problema principal em problemas menores, estes associados e limitados à operação de determinado estágio do Secador de Grãos. A Figura 2 apresenta essa divisão. Cada estágio passou, portanto, à responsabilidade de um grupo de alunos. Ademais, de modo a evidenciar as qualidades de responsabilidade e comprometimento dos estudantes, a solução de cada sub-problema foi planejada de forma a ser dependente da solução do problema do estágio vizinho. Sendo assim, o grupo, além de seu próprio desafio, precisou colaborar para o sucesso do grupo vizinho, todos, por fim, e colaborativamente, chegando a solução geral.

Figura 2 - Fluxograma da Situação-problema

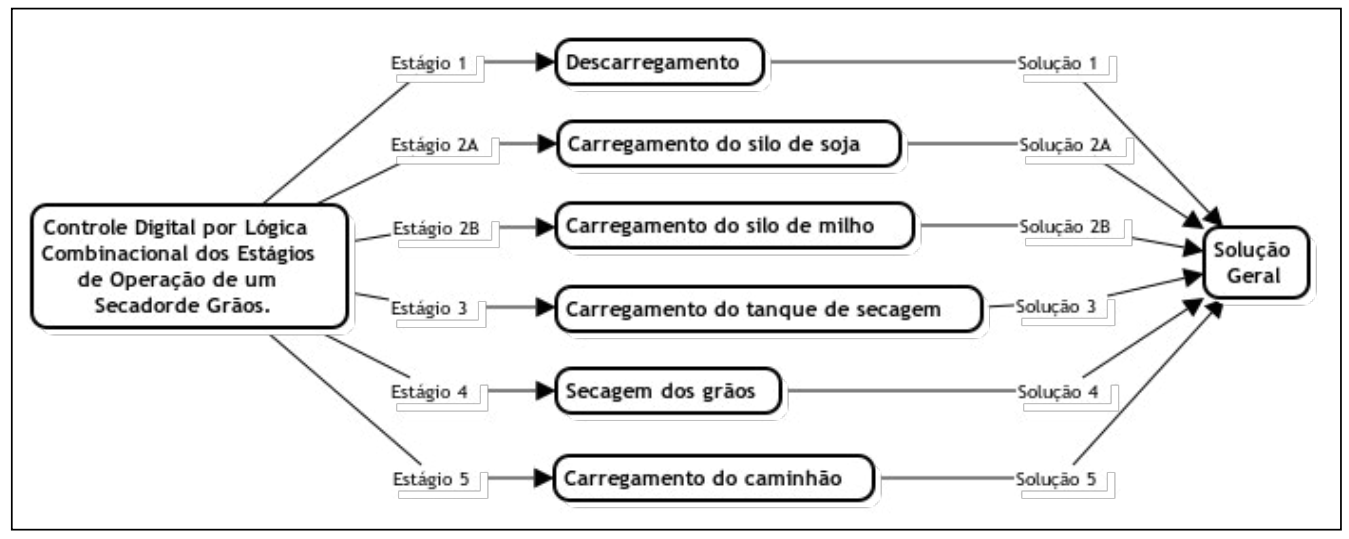

Fonte: Dos autores (2017).

A atividade a ser desenvolvida via PBL foi estruturada em 5 fases como pode ser observado no Quadro 1. Para o cumprimento de cada uma destas fases, destinou-se então um total de cinco encontros. Considerando que o 
período letivo da disciplina compreendeu 18 encontros, as primeiras 13 aulas serviram para a construção do conhecimento necessário para o então avanço à atividade objeto deste estudo. A seguir cada fase é particularizada.

Quadro 1 - Relação de fases desenvolvidas

\begin{tabular}{|l|c|c|c|c|c|c|}
\hline \multirow{2}{*}{ Fases } & \multirow{2}{*}{ Executor } & \multicolumn{4}{|c|}{ Cronograma (Aula) } \\
\cline { 4 - 7 } & & $\mathbf{1 4}^{\mathbf{a}}$ & $\mathbf{1 5}^{\mathbf{a}}$ & $\mathbf{1 6}^{\mathbf{a}}$ & $\mathbf{1 7}^{\mathbf{a}}$ & $\mathbf{1 8}^{\mathbf{a}}$ \\
\hline $\begin{array}{l}\text { 1. Apresentação da situação-problema } \\
\text { e designação dos sub-problemas aos } \\
\text { grupos. }\end{array}$ & Professor & & & & & \\
\hline $\begin{array}{l}\text { 2. Pesquisa e busca por conhecimentos } \\
\text { prévios. }\end{array}$ & Aluno/Grupo & & & & & \\
\hline $\begin{array}{l}\text { 3. Solução do problema de cada grupo: } \\
\text { execução por simulação. }\end{array}$ & Grupo & & & & & \\
\hline $\begin{array}{l}\text { 4. Solução do problema de cada grupo: } \\
\text { execução por montagem prática. }\end{array}$ & Grupo & & & & & \\
\hline $\begin{array}{l}\text { 5. Solução do problema: união das } \\
\text { soluçães práticas (solução geral } \\
\text { integrada). }\end{array}$ & Turma & & & & & \\
\hline
\end{tabular}

Fonte: Dos autores (2017).

A fase 1 foi a mais curta, porém uma das mais importantes. Foi nela que o professor apresentou a situação-problema e fez a primeira orientação quanto à condução da atividade. Por se tratar de uma tarefa em grupos, nesta fase a turma foi dividida em dois grandes grupos de doze alunos. Para cada grande grupo formou-se outros seis subgrupos (duplas), cada um sendo designado a um dos seis estágios do secador de grãos. Importante ressaltar que foi dada total liberdade de interação entre grupos.

Na segunda fase, o aluno, de posse de seu desafio específico, teve autonomia na busca do conhecimento necessário para a resolução de seu problema. Esta etapa de estudo não foi restrita à sala de aula, pelo contrário, o aluno foi incentivado a realizar sua pesquisa no período extra-aula. Procurouse, dessa forma, aproveitar melhor as duas aulas destinadas a esta fase para o desenvolvimento da argumentação, seja ela dentro do grupo, fora dele e com os demais grupos, ou mesmo com o professor. Ao final desta fase, cada grupo já deveria estar de posse da solução teórica de seu problema.

A fase 3 foi especial por ter um intuito diferenciado. Inseriu-se a figura da simulação. O grupo, para corroborar a provável solução teórica constituída na fase anterior, teve condições de simular computacionalmente sua solução usando um conjunto específico de programas de uso educacional e profissional. 
O objetivo principal dessa fase foi aproximar o aluno da realidade profissional onde ferramentas da TIC são comuns. Além disso, como objetivo secundário, esta fase serviria para dar garantias ao grupo quanto a solução construída, ou seja, o grupo avançaria para a próxima fase certo de sua solução, pois pôde comprová-la via simulação computacional. Em caso de falhas na simulação da solução do problema, a equipe deveria retornar à fase anterior para uma nova tentativa.

Foi na quarta fase que cada grupo teve uma atividade mais prática no sentido de interagir com ferramentas e dispositivos eletrônicos reais para a construção e montagem física de seu projeto de solução. Esta foi a etapa mais suscetível a falhas e, portanto, ao consumo de tempo, requerendo assim um empenho e dedicação maior do grupo.

A fase seguinte foi o momento em que os seis grupos tiveram que unir fisicamente suas montagens práticas completando o funcionamento do secador de grãos. Nesta fase ocorreu o ápice da integração dos grupos. Apesar da tensão inicial causada principalmente pelo receio do funcionamento de todos os trabalhos conjuntamente e, ainda, interligados, a situação acabou transformando-se em um momento de grande união por parte dos seis grupos em prol do resultado assertivo.

A condução e a execução da atividade de PBL seguiu o fluxograma da Figura 3. As 5 fases foram inseridas no processo representando checkpoints, ou seja, alcançar uma nova fase significou para o aluno o cumprimento da fase anterior com sucesso. 
Figura 3 - Processos adotados para desenvolvimento da atividade de PBL

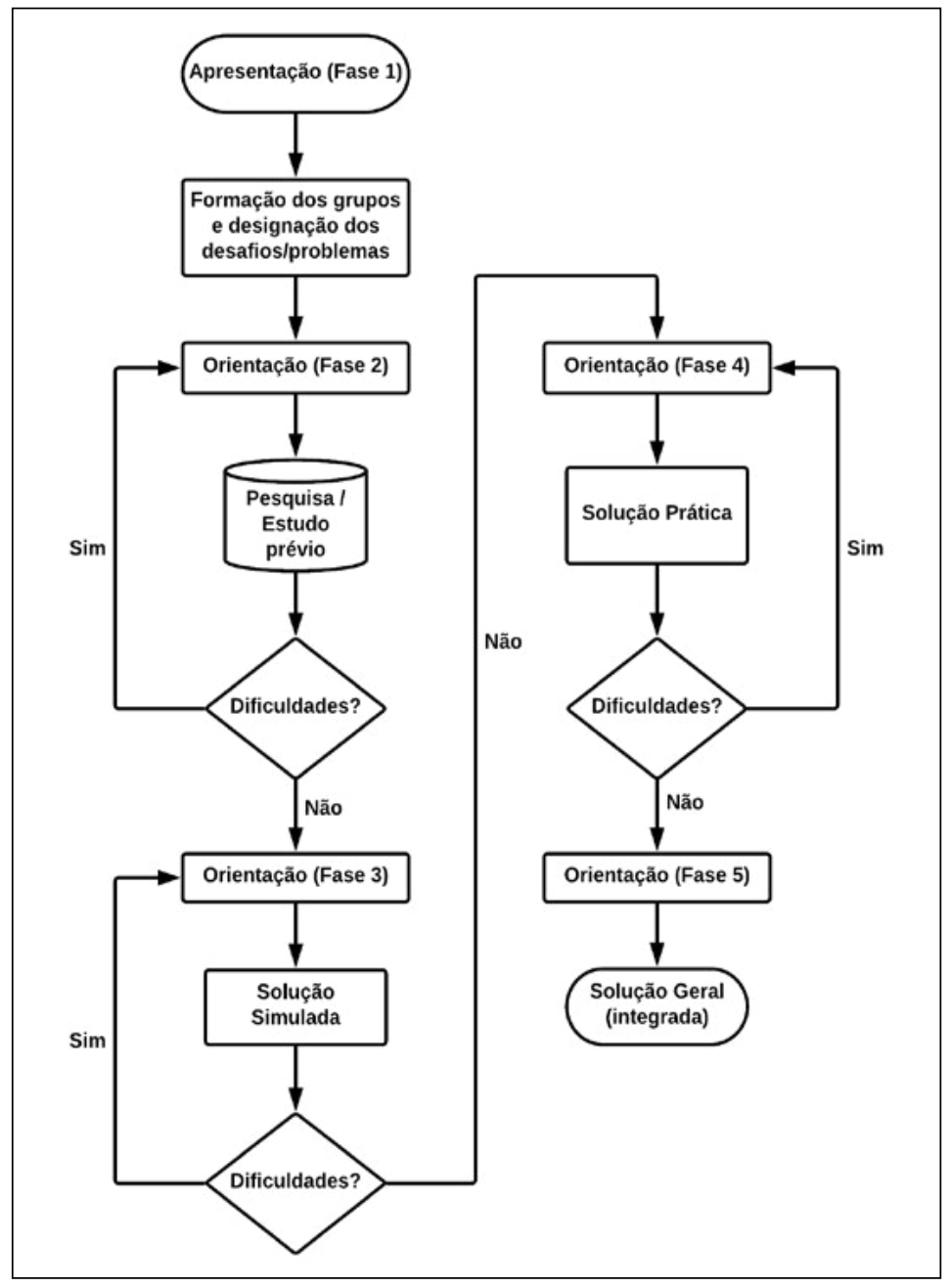

Fonte: Dos autores (2017).

A transição entre as fases envolve duas situações que exigem a presença do professor. A primeira é um processo de decisão cujo intuito é identificar possíveis dificuldades que poderiam travar o avanço do grupo. Tendo sido identificadas, impede-se o avanço e reconduz-se este grupo ao momento de orientação inicial da presente fase. É relevante para a execução da atividade que possíveis dificuldades sejam detectadas com antecedência, evitando, assim, complicações com o cronograma.

A segunda situação parte do pressuposto que o grupo cumpriu a fase anterior sem dificuldades ou com elas devidamente sanadas estando, portanto, apto a prosseguir para a fase seguinte. É neste momento pré-início de fase que 
o grupo passa por uma nova rodada de orientações que lhe darão os subsídios necessários para, de forma autônoma, realizar o próximo desafio.

\section{RESULTADOS E DISCUSSÕES}

Ao desenvolver uma atividade afastada do método tradicional de ensino, requer-se do professor coragem e preparo. Inovar representa dedicação extra, tanto do professor quanto dos alunos. Sendo assim, é preciso que os participantes do processo acreditem no potencial pedagógico e deem valor à iniciativa (BARBOSA; MOURA, 2013). Além do mais, a exemplo deste estudo, tomou-se cerca de $28 \%$ do tempo de aula que poderia ter sido aproveitado da maneira tradicional. Mensurar se a iniciativa correspondeu ao esperado passa a ser importante neste caso.

Portanto, com o intuito de avaliar quali-quantitativamente a relevância do presente estudo no processo de aprendizagem dos alunos e, por consequência, dar subsídios para analisar e questionar se o objetivo do trabalho foi ou não alcançado, cada aluno foi convidado a responder um questionário cujas indagações envolveram a atividade proposta segundo a metodologia PBL.

Com os dados gerados a partir da aplicação do questionário aos 24 alunos da disciplina de Eletrônica Digital (turma 2017A) produziu-se diversos gráficos que a seguir são individualmente analisados, interpretados e os resultados comentados e confrontados com outros estudos da área.

O Gráfico 1 exibe as respostas coletadas dos alunos quanto a percepção destes na contribuição da metodologia PBL para o desenvolvimento da atividade. Para o estudante, problematizar uma situação próxima da sua realidade, desenvolvendo-a com espírito colaborativo e com auxílio de ferramentas de TIC, foi proficiente?

Gráfico 1 - Contribuição da PBL para o desenvolvimento da atividade

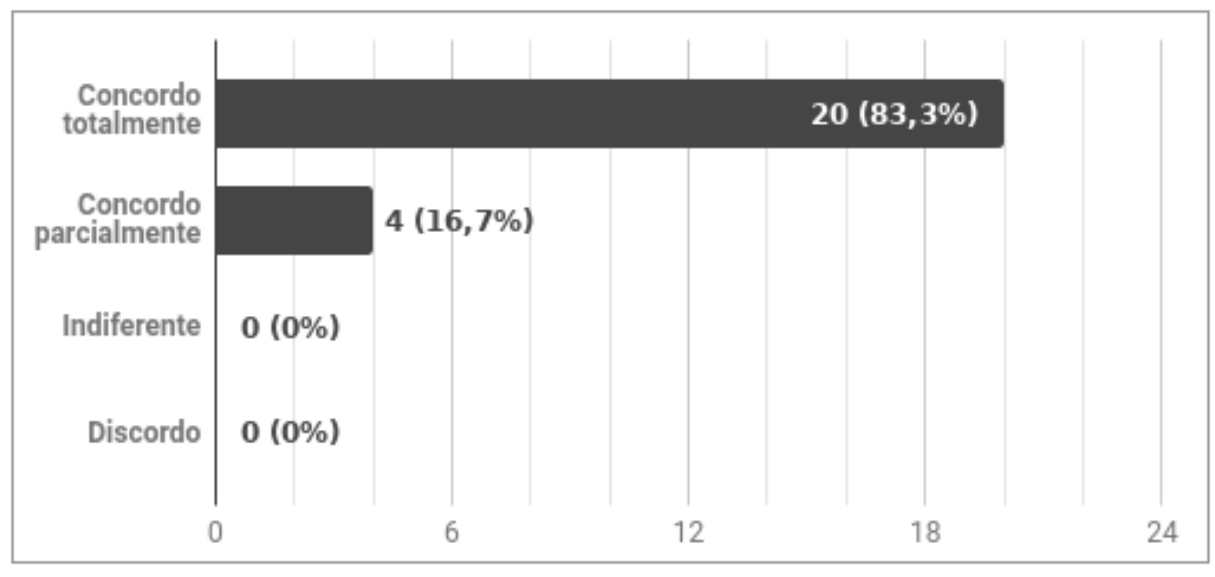

Fonte: Dos autores (2017). 
Dos 24 alunos respondentes, $20(83,3 \%)$, concordaram totalmente, ou seja, acreditam que a metodologia PBL realmente contribuiu para a execução da tarefa. Já $4(16,7 \%)$ alunos consideraram a metodologia como parcialmente representativa. Um ponto relevante foi a inexistência de avaliações que consideraram que a metodologia não contribuiu para o desenvolvimento da atividade.

No Gráfico 2 teve-se um resultado representativo quanto a importância da PBL na aprendizagem do aluno. Essa questão, uma das mais importantes do questionário, teve a intenção de verificar a contribuição da metodologia PBL para a aprendizagem do aluno.

Gráfico 2 - Contribuição da metodologia PBL para a aprendizagem

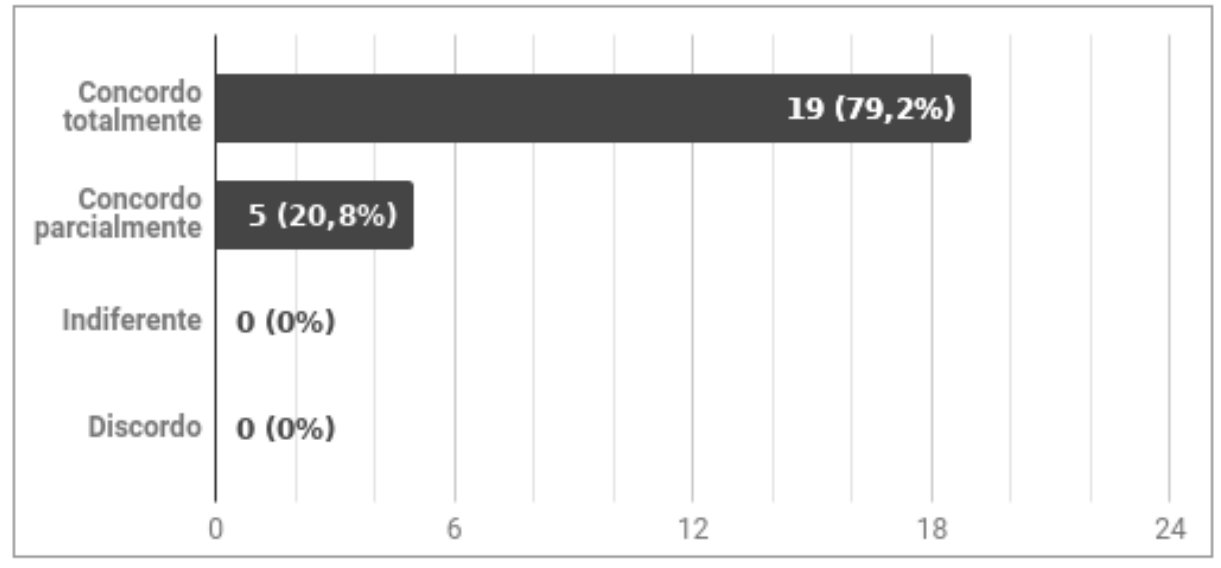

Fonte: Dos autores (2017).

Mais uma vez, a maioria dos alunos $(79,2 \%)$ acredita que a adoção da metodologia baseada em problemas certamente contribuiu para a sua aprendizagem. O restante, $20,8 \%$ da turma considera que teve alguma contribuição em seu processo de aprendizagem.

Estes resultados vão ao encontro do que Barbosa e Moura (2013, p. 65) falam sobre a processo de aprendizagem dos alunos da Educação Profissional que foram expostos à metodologia PBL. Para eles, as experiências de aprendizagem vivenciadas são "[...] muito positivas e o conhecimento adquirido por essa via é de um valor inquestionável em seu processo formativo".

A seguir, analisando o Gráfico 3, verifica-se se a atividade proposta através do método PBL rendeu um aumento no interesse e no envolvimento do aluno na disciplina, ou seja, se este se sentiu motivado para o processo de aprendizagem. O resultado mais uma vez se mostra satisfatório, uma vez que 20 alunos $(83,3 \%)$ concordam totalmente com o questionamento. 
Gráfico 3 - Aumento do interesse e envolvimento na disciplina com a PBL

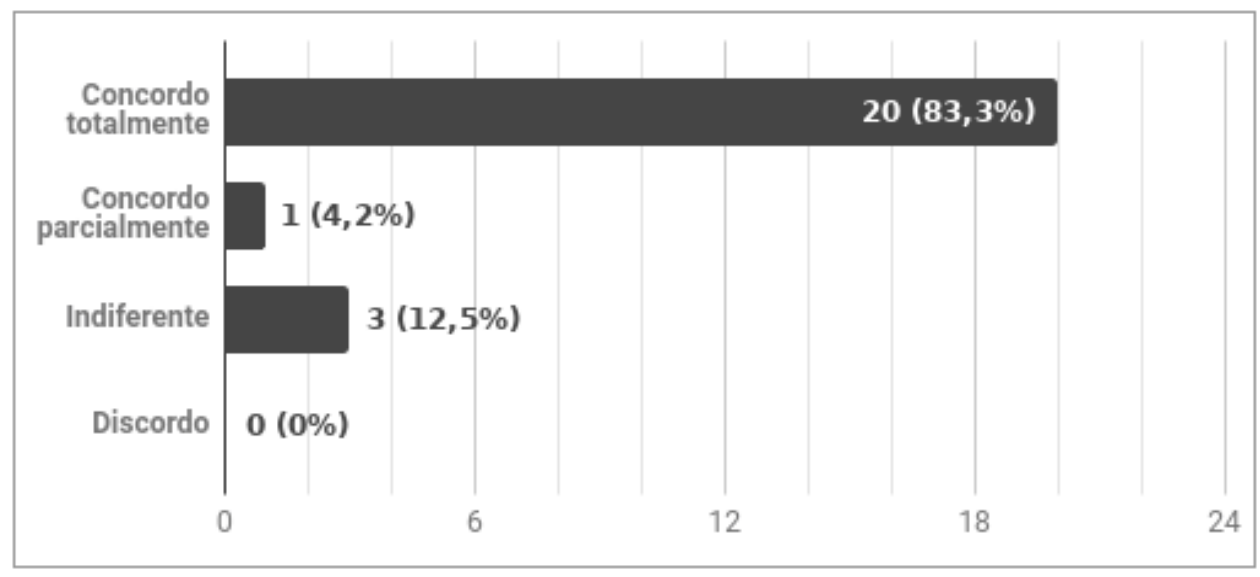

Fonte: Dos autores (2017).

Tais resultados podem ser atribuídos ao método ao referenciarmos Berbel (2011) quando fala do sentimento de motivação e autonomia - que é associado ao termo "autodeterminação" - como uma condição de agir sem controle externo, fazer por vontade própria. Sendo assim, para Berbel (2011, p. 28) a implantação das metodologias ativas:

[...] pode vir a favorecer uma motivação autônoma quando incluir o fortalecimento da percepção do aluno de ser origem da própria ação, ao serem apresentadas oportunidades de problematização de situações envolvidas na programação escolar, de escolha de aspectos dos conteúdos de estudo, de caminhos possíveis para o desenvolvimento de respostas ou soluções para os problemas que se apresentam alternativas criativas para a conclusão do estudo ou da pesquisa, entre outras possibilidades.

Para os $12,5 \%$ dos alunos que não viram em si um interesse, uma motivação maior para a aprendizagem, podemos atribuir a uma possível incapacidade do professor de, segundo Reeve (2009 apud Berbel, 2011, p. 28), não conseguir adotar a perspectiva do aluno, de não acolher seus pensamentos, sentimentos e ações, deixando de apoiar seu desenvolvimento motivacional e capacidade para autorregular-se.

No Gráfico 4 observamos o quanto a característica da PBL de fomentar o trabalho colaborativo se mostrou evidente para os alunos $(83,3 \%)$, enquanto que somente 1 aluno se mostrou indiferente ao trabalho cooperativo. 
Gráfico 4 - Motivação para os estudos por meio das atividades e discussões em grupo

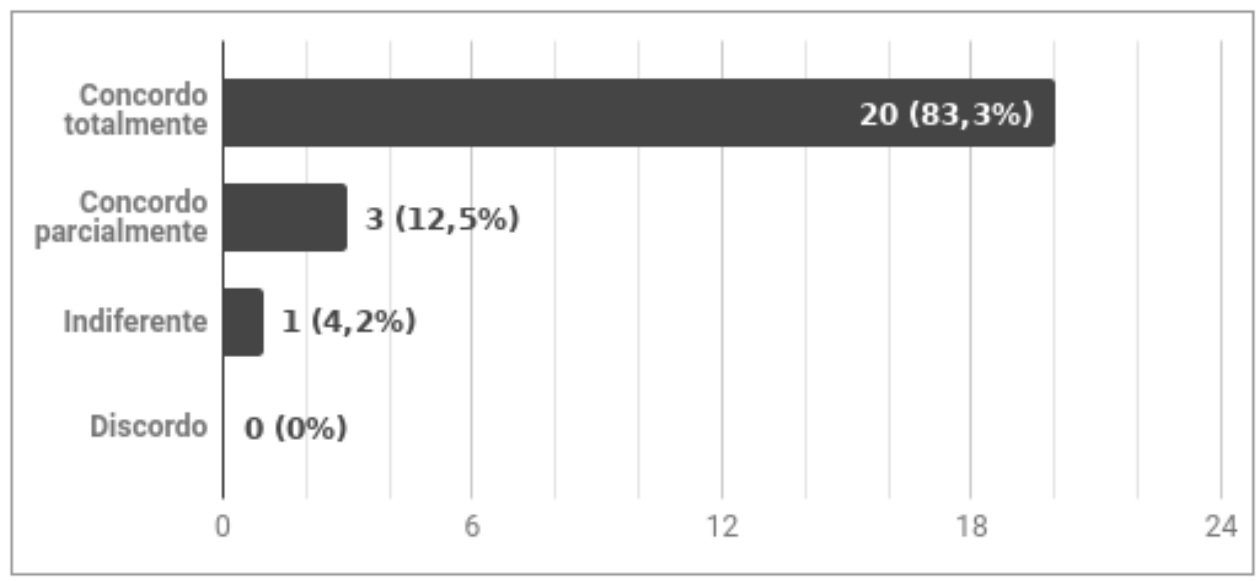

Fonte: Dos autores (2017).

Estes resultados demonstram que, não só por haver a necessidade do próprio grupo obter sucesso em seu desafio, havia o desafio maior, o de integrar a solução de todos os grupos. Isso certamente contribuiu para cada um se empenhar um pouco mais e, se necessário, argumentar e discutir junto aos outros grupos.

Lourenço e Palma (2005 apud Borochovicius e Tortella, 2014, p. 272), afirmam que nas atividades em grupo possibilitam-se trocas de experiências, argumentações, informações e choques de diferentes pontos de vista, que permitem que as situações de conflito cognitivo contribuam para a formação do educando. Para eles, o conflito argumentativo, quando permite o desequilíbrio que motive o discente a melhorar os conhecimentos que já possui, é uma estratégia com resultados positivos no processo ensino-aprendizagem.

Em seguida aborda-se a percepção dos alunos quanto ao tempo destinado para a realização da atividade. O Gráfico 5 demonstra que para 2 alunos as 5 aulas destinadas para a tarefa não foram adequadamente dimensionadas, enquanto que para $70,8 \%$ da turma foi adequado. Para os 4 alunos que concordaram parcialmente, um ajuste deve ser suficiente. 
Gráfico 5 - Destinação de tempo para a realização da atividade

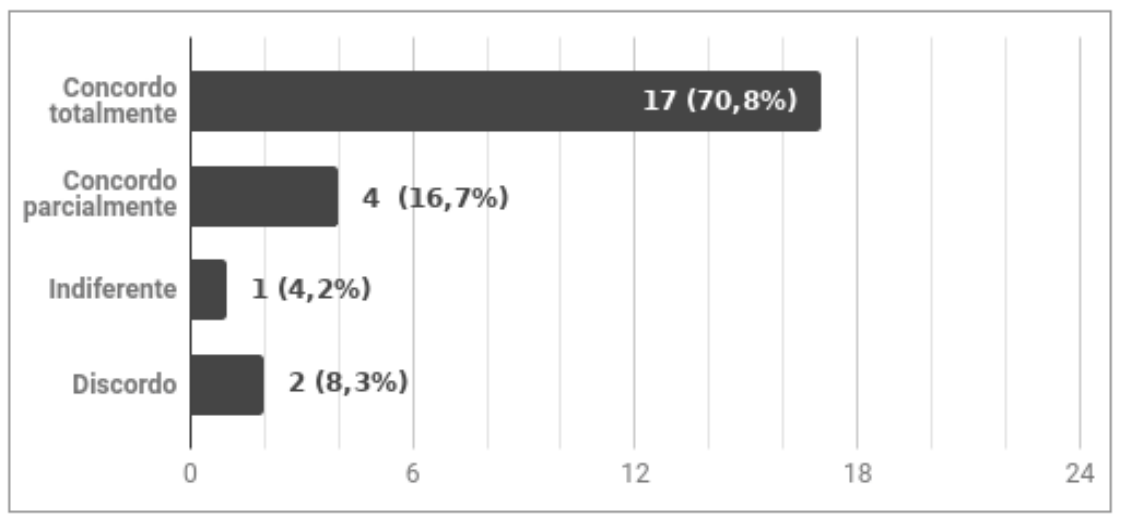

Fonte: Dos autores (2017).

A atividade, por ter uma duração de "algumas semanas", pode ser enquadrada no terceiro de quatro níveis segundo a classificação de Hadgraft e Prpic (1999, apud Ribeiro, 2010, p. 24). Essa alocação de tempo garante, segundo o mesmo autor, uma integração significativa de conceitos e habilidades na solução de problemas, um trabalho em equipe (menos informal que o nível anterior) e orientação por tutores com método formal de solução de problemas.

O Gráfico 6 apresenta algumas características da metodologia PBL ranqueadas de acordo com a quantidade de votos recebidos pelos alunos. Cada aluno teve a oportunidade de escolher 3 características de um total de 11 que, segundo sua avaliação, foram mais representativas em seu processo de aprendizagem enquanto realizava a atividade. 
Gráfico 6 - Características da metodologia PBL

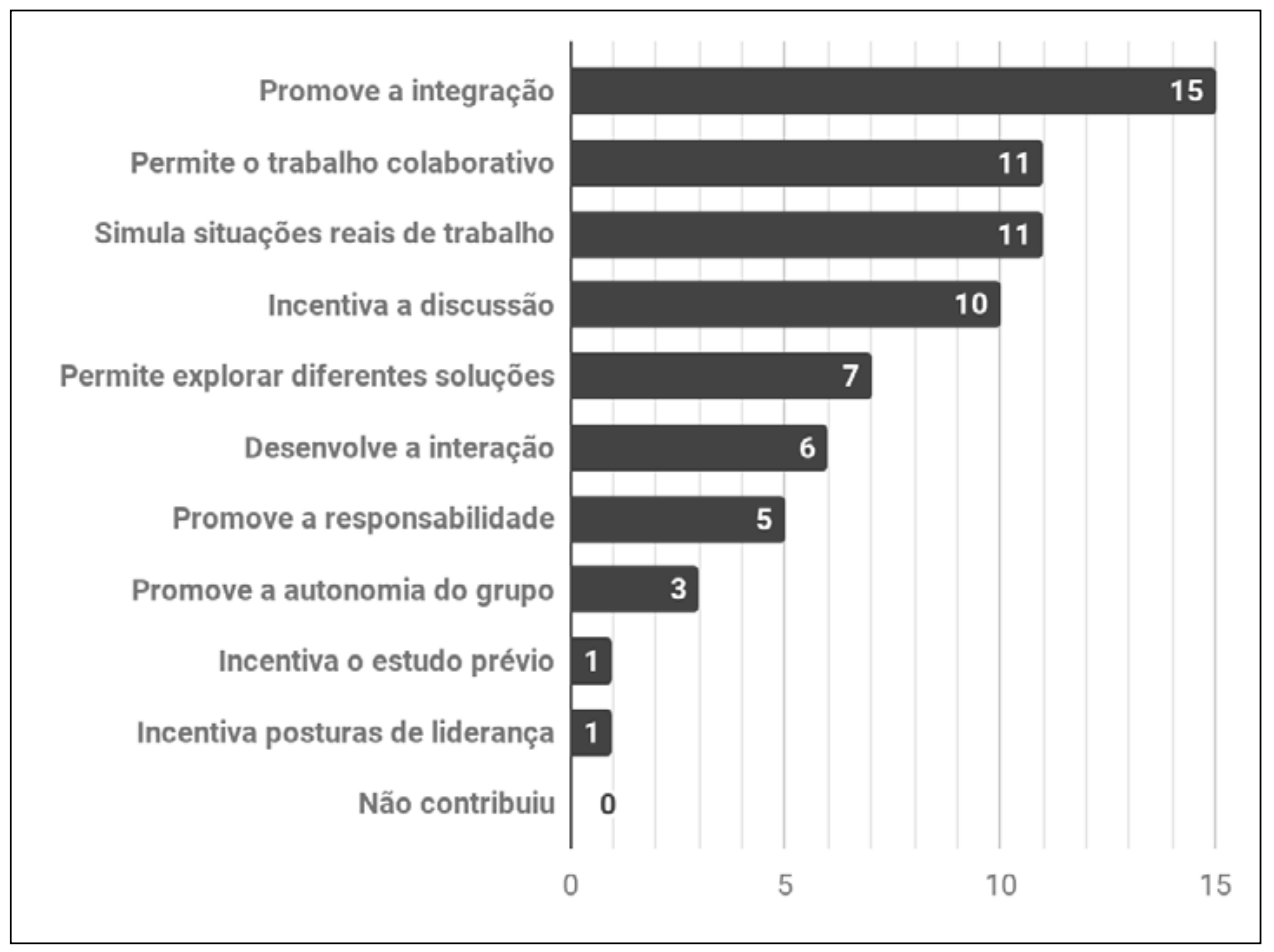

Fonte: Dos autores (2017).

Constata-se que a promoção da integração entre os alunos foi o quesito mais bem avaliado, seguido pelo trabalho colaborativo, simulação de situações reais de trabalho e o incentivo à discussão. Fato importante foi que ninguém, mesmo com a possibilidade de 3 escolhas, optou pela não contribuição da PBL. Pode-se concluir então que, para todos, alguma característica da PBL foi relevante.

A importância dada à integração, ao trabalho em grupo e à discussão pode estar associado ao pensamento de Bleger (1998 apud Borges e Alencar, 2014, p. 135): os integrantes de um grupo “[...] não só aprendem a pensar, como também a observar e escutar, a relacionar suas opiniões com as alheias, a aceitar pensamentos e ideologias diferentes das suas, integrando-se no trabalho em equipe". Ou seja, o integrante de uma equipe de trabalho, ao observar e escutar opiniões alheias, integra-se ao trabalho em grupo no momento em que socializa sua opinião, confrontando-a com as demais e pondo em prática seu poder de argumentação.

No Quadro 2 a seguir estão postados os relatos dos alunos dados livremente numa questão aberta sobre o método PBL. 
Quadro 2 - Comentários e sugestões sobre o método PBL

\begin{tabular}{|l|}
\hline Aluno 1: Promove o trabalho em equipe. \\
\hline Aluno 2: Promove o trabalho em equipe. \\
\hline $\begin{array}{l}\text { Aluno 3: Método de trabalho muito bom e interessante. Ajuda o grupo a se unir } \\
\text { mais e focar mais no assunto abordado, ajudando assim a tirar várias dúvidas que } \\
\text { surgem ao longo do trabalho. }\end{array}$ \\
\hline Aluno 4: Muito bom, espero que os próximos sejam assim. \\
\hline Aluno 5: Muito bom, traz novas ideias e soluções. \\
\hline $\begin{array}{l}\text { Aluno 6: Os trabalhos em grupo durante o semestre foram importantes para a } \\
\text { integração com os colegas além de dar a oportunidade de ver outros pontos de vista } \\
\text { a respeito da solução dos problemas propostos. }\end{array}$ \\
\hline Aluno 7: Teve uma importância muito boa no meu desenvolvimento e do grupo. \\
\hline $\begin{array}{l}\text { Aluno 8: Trabalho foi bom, pena que o tempo com os materiais foi curto. Esses } \\
\text { materiais poderiam ficar à disposição durante a semana para não precisar remontar } \\
\text { toda aula. }\end{array}$ \\
\hline $\begin{array}{l}\text { Aluno 9: Eu acredito que esta metodologia contribui para o desenvolvimento da } \\
\text { disciplina sim, porém eu, particularmente não me adapto muito bem a trabalhos em } \\
\text { grupo, prefiro fazer trabalhos sozinho ou até mesmo provas, que só dependam de } \\
\text { mim para minha nota. }\end{array}$ \\
\hline $\begin{array}{l}\text { Aluno 10: Muito construtivo esse método pois, além de gerar debates construtivos, } \\
\text { promove o raciocínio lógico. }\end{array}$ \\
\hline
\end{tabular}

Fonte: Dos autores (2017).

Como podemos constatar, a característica do trabalho em grupo foi relatada pelos Alunos 1 e 2, enquanto os Alunos 5 e 6 mencionaram a diversidade de ideias e a visualização de múltiplas soluções para os problemas. Pelas declarações, percebe-se a promoção do estudo próprio e da autonomia na busca por soluções alternativas. Certamente temos, para estes casos, também o envolvimento forte do poder de argumentação em prol da melhor solução. O Aluno 10 faz este apontamento em sua citação: "[...] gerar debates construtivos". De modo geral vários alunos ainda falaram da importância da PBL para o desenvolvimento de sua atividade.

\section{CONCLUSÃO}

Com este trabalho buscou-se verificar alternativas à tradicional metodologia expositiva dialogada na formação de estudantes inseridos no Ensino Profissional. Tal ensino, focado na transmissão de conhecimento, de via única, ou seja, do professor para o aluno, foi até então, o método de ensino utilizado para formar os profissionais dedicados a tarefas repetitivas e inertes. Como visto, necessita-se, hoje, de profissionais pensantes, de iniciativa, colaborativos e autônomos, justificando-se a utilização do método ativo de 
aprendizagem baseado em problemas para suprir tal demanda, uma vez que o método se propõe centrar o aluno no processo de aprendizagem, fazendo com que aprenda a aprender por intermédio da reflexão sobre situações que o aproximem de sua vivência cotidiana.

O professor autor, amparado em sua experiência de sala aula e nos resultados deste estudo, considera os tradicionais métodos de ensino, por mais interessantes que o professor possa deixá-los, incapazes de atrair de maneira satisfatória o interesse dos alunos. Envolver situações reais, ou seja, dar uma aplicação prática à teoria sob análise, claramente chama a atenção dos alunos e inicia um processo natural de questionamento e argumentação. Quanto mais essa aplicação prática se aproxima da vivência do aluno, mais desperta a curiosidade e o envolvimento deste.

Diante dos resultados analisados, ao utilizar a metodologia ativa da problematização associada a uma situação contextualizada para o ambiente profissional da área de interesse destes alunos e, dando-lhes a liberdade para aprenderem com a própria solução, permitiu-se observar características como trabalho cooperativo, poder de argumentação, flexibilidade, interesse, autonomia e, o principal, aquele "brilho no olho" característico dos alunos com anseio por apreender.

Por esta constatação, conclui-se que, com a utilização de métodos ativos de aprendizagem focados na problematização de situações reais, de interesse dos alunos, estaremos contribuindo para a formação de profissionais com condições de promover soluções de problemas de forma autônoma e colaborativa, atendendo, assim, às demandas do mundo do trabalho. E, ademais, ao incorporar tais métodos de maneira mais regular nos planos de ensino das instituições de Educação Profissional, estaremos propiciando com que estas se mantenham no eixo das constatadas movimentações sociais.

\section{REFERÊNCIAS}

BARBOSA, Eduardo Fernandes; GONTIJO, Alberto de Figueiredo; SANTOS, Fernanda Fátima dos. Inovações pedagógicas em educação profissional: uma experiência de utilização do método de projetos na formação de competências. Educação \& Tecnologia, v. 8, n. 2, 2003.

BARBOSA, Eduardo Fernandes; MOURA, Dácio Guimarães de. Metodologias ativas de aprendizagem na educação profissional e tecnológica. Boletim Técnico do Senac, v. 39, n. 2, p. 48-67, 2013.

BERBEL, Neusi Aparecida Navas. As metodologias ativas e a promoção da autonomia de estudantes. Semina: Ciências Sociais e Humanas, v. 32, n. 1, p. 25-40, 2011.

BORGES, Tiago Silva; ALENCAR, Gidélia. Metodologias ativas na promoção da formação crítica do estudante: $\mathrm{o}$ uso das metodologias ativas como recurso didático 
na formação crítica do estudante do ensino superior. Cairu em Revista, v. 3, n. 04, p. 119-143, 2014.

BOROCHOVICIUS, Eli; TORTELLA, Jussara Cristina Barboza. Aprendizagem Baseada em Problemas: um método de ensino-aprendizagem e suas práticas educativas. Ensaio: Avaliação e Políticas Públicas em Educação, v. 22, n. 83, 2014. Disponível em: <http:/ / www.redalyc.org/articulo.oa?id=399534054002> . Acesso em: 21 fev. 2018. ISSN 0104-4036.

BRASIL. Catálogo Nacional de Cursos Técnicos. Ministério da Educação. 2008. Disponível em: <http:/ / portal.mec.gov.br/setec/arquivos/pdf3/catalogo_tecnicos. pdf $>$. Acesso em: 21 jan. 2017.

BRASIL. Lei n 9.394, de 20 de dezembro de 1996. Estabelece as Diretrizes e Bases da Educação Nacional. Disponível em: <http:/ / www.planalto.gov.br/ccivil_03/Leis / L9394.htm>. Acesso em: 21 jan. 2017.

BRASIL. Resolução n ${ }^{\circ}$ 6, de 20 de setembro de 2012. Define Diretrizes Curriculares Nacionais para a Educação Profissional Técnica de Nível Médio. Ministério da Educação. Conselho Nacional de Educação. Disponível em: <http:/ / portal.mec. gov.br/index.php?option=com_docman\&view=download\&alias=11663-rceb006-12pdf\&category_slug=setembro-2012-pdf\&Itemid=30192> . Acessado em: 27 fev. 2018.

DIESEL, Aline; MARCHESAN, Michele Roos; MARTINS, Silvana Neumann. Metodologias ativas de ensino na sala de aula: um olhar de docentes da educação profissional técnica de nível médio. Revista Signos, [S.1.], v. 37, n. 1, jun. 2016. ISSN 1983-0378. Disponível em: <http:/ / univates.br/revistas/index.php/signos/article/ view/1008>. Acesso em: 17 fev. 2018. doi:http://dx.doi.org/10.22410/issn.1983-0378. v37i1a2016.1008.

DIESEL, Aline; BALDEZ, Alda Leila Santos; MARTINS, Silvana Neumann. Os princípios das metodologias ativas de ensino: uma abordagem teórica. Revista Thema, [S.1.], v. 14, n. 1, p. 268-288, fev. 2017. ISSN 2177-2894. Disponível em: <http:/ / revistathema.ifsul.edu.br/index.php/thema/article/view/404/295>. Acesso em: 03 ago. 2017. doi:http://dx.doi.org/10.15536/thema.14.2017.268-288.404.

MARTINS, Daiana Bragueto. Avaliação de habilidades e de atitudes em abordagem de problem-based learning no ensino de controle gerencial. 2013. Dissertação (Mestrado em Contabilidade) - Universidade Federal do Paraná, Curitiba, 2013. Disponível em: <http:/ / acervodigital.ufpr.br/bitstream/ handle/1884/34593/R\%20-\%20D\%20-\%20DAIANA\%20BRAGUETO\%20MARTINS. pdf? sequence $=1 \&$ is Allowed $=y>$. Acessado em: 28 fev. 2018.

MORÁN, José. Mudando a educação com metodologias ativas. In: SOUZA, Carlos Alberto de; MORALES, Ofelia Elisa Torres (orgs.). Coleção Mídias Contemporâneas. Convergências Midiáticas, Educação e Cidadania: aproximações jovens. Vol. II. PG: Foca Foto-PROEX/UEPG, 2015. Disponível em: <http:/ /www2.eca.usp.br/moran/ wp-content/uploads/2013/12/mudando_moran.pdf>. Acesso em: 18 fev. 2018. 
OLIVEIRA, Agostinho C.; ARAÚJO, Samira M. Métodos Ativos de Aprendizagem: uma breve introdução. 2015. Disponível em: <https:/ / www.researchgate.net/ publication/280091153_Metodos_Ativos_de_Aprendizagem_uma_breve_ introducao>. Acessado em: 21 jan. 2017. doi: 10.13140/RG.2.1.5004.6561

RIBEIRO, Luis R. de Camargo. Aprendizagem Baseada em Problemas (PBL): Uma experiência no ensino superior. São Carlos: EdUFSCar, 2010.

SOUZA, Samir Cristino de; DOURADO, Luis. Aprendizagem Baseada em Problemas (ABP): Um Método de Aprendizagem Inovador para o Ensino Educativo. HOLOS, [S.1.], v. 5, p. 182-200, out. 2015. ISSN 1807-1600. Disponível em: <http:/ / www2. ifrn.edu.br/ojs/index.php/HOLOS/article/view/2880>. Acesso em: 03 mar. 2018. doi:https:/ / doi.org/10.15628/holos.2015.2880. 